\title{
Practice makes perfect: Practice engagement theory and the development of adult literacy and numeracy proficiency
}

\author{
Stephen Reder ${ }^{1}\left(\mathbb{0} \cdot\right.$ Britta Gauly $^{2}\left({ }^{\circ} \cdot\right.$ Clemens Lechner $^{2}(1)$
}

Published online: 24 April 2020

(c) The Author(s) 2020

\begin{abstract}
Practice engagement theory (PET) posits that individuals' literacy proficiencies develop as a by-product of their engagement in everyday reading and writing practices and, reciprocally, that literacy proficiencies affect levels of engagement in reading and writing practices. This suggests that literacy training which increases engagement in meaningful practices might generate proficiency growth. Research has shown that this approach does indeed seem to be effective in improving (adult) learners' literacy proficiency. A number of cross-sectional comparisons of participants' and non-participants' performance in various training activities, as well as quantitative modelling of adults' proficiency growth in longitudinal studies have confirmed the theoretical assumptions of PET. The authors of this article describe the first application of PET to literacy and numeracy development in a longitudinal study of a nationally representative adult population. Their investigation followed a sample of adults initially interviewed and assessed in the German component of the Programme for the International Assessment of Adult Competencies (PIAAC), adding longitudinal data from three additional waves of the national extension study (PIAAC-L), which included repeated assessments of literacy and numeracy proficiency over a period of three years. The authors' quantitative modelling of the growth of literacy and numeracy proficiency over time provides strong support for PET. Their comparisons of how various practice engagement indexes predict growth of literacy and numeracy proficiencies indicate that reading engagement is the strongest predictor of literacy growth and maths engagement is the strongest predictor of numeracy growth. The authors conclude their article by considering their findings' implications for sustainable development, lifelong learning policy and future research into the development of adult literacy and numeracy proficiency.
\end{abstract}

Keywords adult $\cdot$ literacy $\cdot$ numeracy $\cdot$ proficiency $\cdot$ practices $\cdot$ Programme for the International Assessment of Adult Competencies (PIAAC) · longitudinal data

Stephen Reder

reders@pdx.edu

Extended author information available on the last page of the article 


\section{Résumé}

C'est en forgeant que l'on devient forgeron : théorie de l'engagement pratique et développement de la littératie et de la numératie chez les adultes - La théorie de l'engagement pratique postule que le niveau individuel de littératie évolue accessoirement avec l'engagement de la personne dans des activités de lecture et d'écriture et que, réciproquement, le niveau de littératie se répercute sur l'engagement de l'individu dans des activités de lecture et d'écriture. Ceci indique que l'alphabétisation, qui accroît l'exercice d'activités utiles, pourrait induire une amélioration du niveau de compétences. Des recherches ont montré que cette approche semble vraiment efficace pour améliorer le niveau de littératie des apprenants (adultes). Un ensemble de comparaisons transversales des résultats obtenus par des participants et des non participants à différentes activités de formation ainsi qu'une modélisation quantitative de l'évolution du niveau de compétences des adultes réalisée dans le cadre d'études longitudinales ont confirmé les hypothèses postulées par la théorie de l'engagement pratique. Les auteurs de cet article décrivent, dans une étude longitudinale portant sur un échantillon d'adultes représentatif au plan national, la première application de la théorie de l'engagement pratique au développement de la littératie et de la numératie. Ils ont pour cela suivi un échantillon d'adultes qu'ils ont initialement interrogés et évalués sur la base de la composante allemande du Programme d'évaluation internationale des compétences des adultes (PIAAC-Programme for the International Assessment of Adult Competencies) en ajoutant des données longitudinales extraites de trois volets supplémentaires de l'étude allemande supplémentaire (PIAAC-L) qui comportait des évaluations répétées des niveaux de littératie et de numératie sur une période de trois ans. La modélisation quantitative de l'amélioration au fil du temps des niveaux de littératie et de numératie que les auteurs ont réalisée étaye avec force la théorie de l'engagement pratique. Ils livrent des comparaisons sur la façon dont différents indices d'engagement pratique annoncent l'amélioration des niveaux de littératie et de numératie. Ces comparaisons révèlent que la pratique de la lecture est le plus puissant indicateur d'amélioration de la littératie de même que la pratique des mathématiques est le plus puissant indicateur d'amélioration de la numératie. Les auteurs concluent leur article en envisageant les implications des résultats de leurs recherches pour le développement durable, la politique d'apprentissage tout au long de la vie et les recherches à venir sur le développement de la littératie et de la numératie chez les adultes.

\section{Introduction}

There is a large body of evidence documenting the importance of adult literacy and numeracy for a broad range of economic and social outcomes (Dinis da Costa et al. 2014; Hanushek et al. 2015; Hanushek and Woessman 2015; OECD 2013, 2016). 
Literacy and numeracy proficiencies ${ }^{1}$ have been linked to employment, earnings, health status, social trust, political efficacy and civic engagement. Even after taking educational attainment into account, ${ }^{2}$ strong relationships are apparent between proficiency levels and economic and social outcomes. At the macro level, growth of a country's national gross domestic product (GDP) has been associated with increasing levels of literacy and numeracy proficiency (Schwerdt and Wiederhold 2018). Franziska Hampf et al. (2017) have provided various kinds of converging evidence that the observed relationships between proficiencies and economic outcomes are causal in nature.

Beyond supporting important economic and social outcomes, literacy and numeracy proficiency are essential for sustainable development. High levels of adult literacy and numeracy are an integral part of the United Nations Sustainable Development Goal (SDG) 4, being both prerequisites for and the by-product of lifelong learning. Policies and programmes that foster increased literacy and numeracy proficiencies effectively support SDG 4, which calls on Member States to "ensure inclusive and equitable quality education and promote lifelong learning opportunities for all" (UIS 2018, p. 7).

Forecasts of - and policy frameworks for increasing - future literacy and numeracy levels of adult populations and workforces are generally based on changes in the literacy and numeracy levels of children leaving school in the future (Hanushek and Woessman 2015; Vézina and Bélanger 2019). Although these future schooling outcomes are undeniably a key component of future adult proficiency levels, not enough attention is generally paid to changes over time in the proficiency levels of adults who are already beyond the reach of the school system. The majority of the 2030 workforce, for example, has already completed its education, so changes in their proficiency levels over time will form a major component of the change in proficiency levels among the overall population between now and then. To take this component of future change into account, we need to know much more about how adults' proficiencies change across the lifespan and how various activities, policies and incentives may shape these changes.

Our theoretical framework for this article is practice engagement theory (PET) (Reder 1994; Sheehan-Holt and Smith 2000), which provides a testable account of how proficiency may change during adulthood. It holds that frequent engagement in reading, writing and maths activities fosters the growth of underlying literacy and numeracy proficiencies. As we will demonstrate, PET has important implications for lifelong learning and SDG 4, providing a broad framework which is suitable for designing effective policy and programmatic interventions that foster proficiency growth.

\footnotetext{
${ }^{1}$ We use the term "proficiency" in this article, noting that some other authors use "skills" or "competence" for the same construct. We also use the term "practice engagement", whereas some other authors use "skill use".

${ }^{2}$ Educational attainment refers to the highest level of formal education a person has successfully completed.
} 
PET has been rigorously tested with data from a longitudinal study of a random sample of a population with a low level of education in a metropolitan area in the United States (Reder 2009a). It also has empirical support from large-scale crosssectional studies of national adult populations (Jonas 2018; Sheehan-Holt and Smith 2000). However, due to data limitations, PET has not yet been tested longitudinally with a broad, nationally representative population sample. The study we present in this article contributes to the empirical literature on proficiency development in adulthood and presents the first test of PET using a nationally representative population.

\section{Proficiency development in adults}

A large body of research has investigated how literacy and numeracy proficiencies develop across the adult lifespan, and there is multi-disciplinary literature which has examined proficiency development from diverse perspectives, identifying a number of possible mechanisms underlying observed changes across the lifespan, across countries and across time (Desjardins and Warnke 2012; Green 2013). Other researchers (Barrett and Riddell 2016; Green and Riddell 2013) have examined proficiency change and ageing. Scholars of work-based learning (e.g. Billett 2004; Skule 2014) have focused on the characteristics of jobs and workplaces that foster learning and proficiency development. Marco Paccagnella (2016) examined the decline of proficiencies in older adults and conceptualised how various employment practices and policies may affect proficiency decline. Several researchers have examined proficiency development in terms of skills obsolescence and career interruption, and have identified a variety of underemployment situations and career interruptions that foster proficiency loss (Bynner and Parsons 1998; de Grip and van Loo 2002; Edin and Gustavsson 2008).

The effects of a variety of interventions in adult life on proficiency development have also been studied. The second and third authors of this article (Gauly and Lechner 2019; Gauly et al. forthcoming) have examined the impact of workrelated training on the development of literacy and numeracy proficiency. They found that the frequently reported positive association between training and proficiency results from a selection effect (i.e., those with higher proficiencies are more likely to enter training) rather than from a causal effect of training on proficiency. Others have studied the impact of adult basic education on proficiency development in adults with low levels of proficiency or education (Brooks et al. 2001; Reder 2009b, 2019a; Sheehan-Holt and Smith 2000; Wolf and Jenkins 2014) and have produced inconsistent findings about whether programme participation has a significant impact on proficiency development. 


\section{Practice engagement theory}

We argue that PET can help make this body of research on adult proficiency development more coherent. PET specifies how engagement in reading, writing and maths activities in everyday life (whether at work or outside of work contexts) affects literacy and numeracy proficiency development over time in the adult lifespan. PET was initially based on cross-cultural and cross-situational qualitative research on literacy practices and proficiencies. It posits that individuals' literacy proficiencies develop as a by-product of their engagement in everyday reading and writing practices and, reciprocally, that literacy proficiencies affect levels of engagement in reading and writing practices (Reder 1994). Quantitative modelling of PET became possible as large-scale surveys started to measure literacy and numeracy proficiencies along with the use of those proficiencies in everyday practices at work and outside of the workplace (Sheehan-Holt and Smith 2000; Smith 1996, 2009). Research conducted by Nicolas Jonas (2018) is among the few studies using these data that apply path model $s^{3}$ to identify significant reciprocal influences between numeracy proficiency and engagement in maths practices, a pattern he terms a "virtuous circle".

More robust support for PET came from a longitudinal study of an adult population with a low level of education that followed individuals in the United States over eight years with repeated measurements of both literacy proficiency and engagement in reading and writing practices (Reder 2009b, 2019a). Cross-lagged structural equation models ${ }^{4}$ were fitted to these panel data, ${ }^{5}$ showing statistically significant positive effects of practice engagement on proficiency change and reciprocal positive effects of proficiency on changes in practice engagement.

The reciprocal linkage between proficiency and practice engagement that characterises PET enables practice engagement to mediate relationships between experiences in adult life and proficiency development. This is theoretically and practically important because there is considerable evidence that practice engagement is more malleable than proficiencies. This means that programmes, policies and interventions can target short-term changes in practice engagement levels, with the expectation that, through the mechanism of PET, these will effect longer-term changes in proficiency. For example, in analysing the impact of adult basic education programmes on students' proficiency trajectories, the first author of this article (Reder 2009b) and Janet Sheehan-Holt and Cecil Smith (2000) found that programmes have a short-term impact on students' levels of practice engagement in the first year after programme exit, but no significant short-term effect on proficiency change. Over time, however, programmes have a substantial impact on proficiency change when assessed five years after programme exit, due to the long-term mediating effects of

\footnotetext{
3 A path model describes directed dependencies among a set of variables. The strength of these dependencies can be estimated with a range of statistical methods including multiple regression, factor analysis, analysis of covariance, and so on.

4 A cross-lagged structural equation model describes how successive values over time of one variable (e.g., literacy proficiency) are related to previous values of the variable and to successive values of another variable (e.g., reading engagement).

5 Panel data are repeated observations of the same individuals over time.
} 
programme-generated change in practice engagement (Reder 2019a). This helps us understand why several other studies of the impact of adult basic education programmes have had inconsistent results. When programmes are assessed for impact at relatively short follow-up intervals, these assessments tend to show non-significant effects (e.g. Wolf and Jenkins 2014); while follow-ups after 3 years (e.g. Brooks et al. 2001) show small but significant effects; and 5-year follow-ups show substantial effects of participation on proficiency growth (Reder 2019a).

In testing PET with the longitudinal data collected in the German national extension study, PIAAC-Longitudinal (PIAAC-L), ${ }^{6}$ we asked several research questions:

(1) Is adults' engagement in reading practices associated with the development of their literacy proficiency over time? How about their engagement in maths practices or writing practices?

(2) Is adults' engagement in maths practices associated with the development of their numeracy proficiency over time? How about their engagement in reading practices or writing practices?

\section{Methods}

\section{The PIAAC-L survey}

For our analysis, we used data from Round 1 of the First Cycle of the Programme for the International Assessment of Adult Competencies (PIAAC), conducted in 23 countries, including Germany, in 2011-2012. Initiated by the Organisation for Economic Co-operation and Development (OECD), PIAAC is an international "adult skills" survey that measures general proficiencies, including literacy and numeracy, in the adult population (age 16-65 years). ${ }^{7}$ We focused on the German PIAAC sample in order to use additional data available from the national extension study, PIAAC-Longitudinal (PIAAC-L). ${ }^{8}$ The target population in the German PIAAC studies were adults who were randomly selected from local population registers in randomly selected municipalities in Germany.

\footnotetext{
${ }^{6}$ For more information on PIAAC-L, visit https://www.gesis.org/en/piaac/rdc/data/piaac-longitudinal [accessed 5 March 2020].

7 For more information, see https://www.oecd.org/skills/piaac/about/\#d.en.481111 [accessed 6 March 2020].

8 According to the project website, "The Leibniz-Institute for the Social Sciences (GESIS), the Leibniz Institute for Educational Trajectories (LIfBi), and the German Socio-Economic Panel (SOEP) conducted one of the world's first internationally comparable long-term studies on competencies in adults and their significance over the life course. How do individual competencies impact on the employment careers of people living in Germany? How are personal abilities interrelated with occupational mobility? How are competencies distributed between individual families and between partners? And what does this mean for chances of upward mobility in our society? These and similar questions were examined by the nationwide long-term study PIAAC-L (Programme for the International Assessment of Adult Competencies) ... In PIAAC-L the German PIAAC sample was followed over three more waves $(2014,2015,2016)$ ") (GESIS n.d.).
} 
PIAAC-L comprises three waves of data collection in 2014, 2015 and 2016, with the second wave in 2015 also containing a repeated proficiency assessment. This enabled us to investigate the effects of practice engagement on proficiency change. We combined data from the years 2012 and 2015 because these contained the proficiency assessments as well as the information on engagement with reading, writing and maths tasks we required for our analyses. We only considered the native German-speaking population. ${ }^{9}$ Our sample consisted of 2,989 individuals for whom we had complete information in 2012 and 2015 on all analytical variables.

\section{Variables used in modelling}

\section{Dependent variables}

The dependent variables in our models are literacy and numeracy, each assessed in PIAAC 2012 and again in PIAAC-L 2015. PIAAC(-L)'s assessment of literacy and numeracy is based on respondents' answers to sets of cognitive items of varying difficulty. Based on these responses, the OECD derived ten plausible values for literacy proficiency and ten for numeracy proficiency, all on 0-500-point scales (OECD 2013). Further information about the literacy and numeracy assessment frameworks, scaling methodology and sample cognitive items used in PIAAC are available in OECD (2013), PIAAC Literacy Expert Group (2009) and PIAAC Numeracy Expert Group (2009).

\section{Practice engagement variables}

PIAAC collected self-reported frequencies of performing specific tasks involving reading, writing and maths.

The eight reading tasks were:

Read ...

- directions or instructions

- letters, memos or e-mails

- articles in newspapers or magazines

- articles in professional journals or publications

- books

- manuals or reference materials

- bills, invoices, bank statements or other financial statements

- diagrams, maps or schematics

The four writing tasks were:

\footnotetext{
9 We excluded non-native German speakers because their practice engagement refers to any language while their proficiencies were assessed in German.
} 
Write ...

- letters, memos or e-mails

- articles

- reports

- fill in forms

The six maths tasks were:

- Calculate prices, costs or budgets

- Use or calculate fractions, decimals or percentages

- Use a calculator, either hand-held or computer-based

- Prepare charts, graphs or tables

- Use simple algebra or formulas

- Use more advanced mathematics or statistics such as calculus, complex algebra, trigonometry or regression techniques

Respondents indicated, on a five-point Likert scale, how often they performed each task:

- Never

- Less than once a month

- Less than once a week but at least once a month

- At least once a week but not every day

- Every day

All respondents were asked how often they performed each task outside of work, and, if they were currently working, how often they performed each task at work. We created new derived practice engagement (skill use) variables which merged activities across the at-work and outside-of-work contexts. For each task, the greater usage frequency reported between work and outside-of-work contexts becomes the frequency for that merged context item. For example, if an individual reported reading newspapers or magazines "every day" at work and "once a week" outside of work, then the merged frequency would be "every day". For individuals who were not employed at the time of the interview, the merged frequency was just the outside-of-work frequency. ${ }^{10}$ We then used the partial credit model of item response

\footnotetext{
${ }^{10}$ We decided to merge data across contexts for several reasons. First, the overall (merged-context) level of practice engagement was of theoretical interest in our analysis. Second, there are indications that individuals who are working tend to substitute some reading behaviours between non-work and work contexts. Finally, the merged context measures allowed us to analyse the entire adult population rather than just the currently employed subpopulation for which the separate work context engagement measures were available. Similar merged-context measures of practice engagement were used in an earlier study with PIAAC data from the United States (Reder 2019b).
} 
theory $^{11}$ (Hamel et al. 2016; Masters 1982) to scale these merged frequency items into an overall index of breadth and frequency of reading engagement (RE). We used the same procedure to create merged writing engagement (WE) and maths engagement (ME) indices. These index variables were scaled with means set to 0 .

\section{Covariates}

In order to control for confounding factors in the relationship between practice engagement and proficiency, we included the following set of covariates in our analyses:

- Age: Respondents' age in years at time of 2012 interview.

- Gender: Binary flag = 1 if female, 0 if male.

- Education: Years of schooling corresponding to the highest level of educational attainment in 2012.

- Employed: Binary flag = 1 if employed at time of 2012 interview, otherwise 0 .

- Educational Gain: Binary flag = 1 if the educational attainment reported in 2015 is higher than in 2012, otherwise 0 .

\section{Analytical methods}

We analysed the growth of literacy proficiency between 2012 and 2015 as well as the growth of numeracy proficiency from 2012 to 2015 using ordinary least squares (OLS) regression models of the difference between the proficiency at the two points in time. For each proficiency, we examined eight models, all of which used the difference in the assessed proficiency between 2012 and 2015 as the dependent variable and a common set of independent variables including the respective proficiency assessed in 2012 and the five covariates specified in the preceding section. The eight models differ in terms of which, if any, measures of practice engagement are included as independent variables.

The baseline model for each proficiency has no added practice engagement measures. The additional seven models of proficiency growth include three that contain one of the practice engagement measures (RE, WE, ME), three containing two of those measures and one with all three of the practice engagement measures included. In all of our models we accounted for both the complex sample design of PIAAC-L and the measurement error present in the literacy and numeracy assessments at each point in time, ${ }^{12}$ with the latter taking into account the ten plausible values for each proficiency domain.

\footnotetext{
${ }_{11}$ A partial credit model of item response theory estimates values of an underlying variable (e.g., overall reading engagement) from ordered responses (e.g., Never; Less than once a month; Less than once a week but at least once a month; At least once a week but not every day; Every day) to a set of individual items (e.g., how often individuals perform each of the queried reading tasks).

${ }^{12}$ We estimated the regression models using the REPEST procedure in STATA 15 (Avvisati and Keslair $2017[2014])$.
} 
A key question in modelling the growth of literacy proficiency is whether RE is a significant positive predictor of gain in literacy proficiency (2012 to 2015), with literacy proficiency in 2012 and the five covariates controlled. We examined the statistical significance of the RE coefficient that is added to the baseline model. We also compared how well the literacy growth model fits, with and without RE. Since the baseline model is nested within the model with RE added, we used likelihood ratios to test if the added RE term generated a statistically significant improvement in model fit (Wilks 1938) compared to the baseline model. The hypothesis ${ }^{13}$ we tested is that the two models fit the data equally well.

We used a similar approach to examine the estimated models of numeracy growth between 2012 and 2015. We were particularly interested in whether ME was a significant positive predictor of numeracy proficiency gain between 2012 and 2015 , with numeracy proficiency in 2012 and the five covariates controlled. In addition to testing the significance of the ME coefficient, we used the likelihood ratio test to compare how well the numeracy growth model fits, with and without ME included.

\section{Results}

\section{Descriptive statistics for proficiency, practice engagement and covariate variables}

Table 1 displays the means and standard deviations for the proficiency and practice engagement variables, as well as for the five covariates. It is worth noting that the literacy and numeracy variables were assessed in both 2012 and 2015, whereas the practice engagement variables RE, WE and ME and the covariates age, gender, education and current employment were measured only in 2012. One covariate, educational gain, served as a binary flag for an increase in an individual's total years of education between 2012 and 2015.

Table 1 shows little overall change in either the population's literacy proficiency or its numeracy proficiency between 2012 and 2015. We will return to this point below. The practice engagement variables are each scaled to have mean 0 , as shown in the table. The average age of the target population in 2012 was 42 . Nearly half $(49 \%)$ of the population was female. The average number of years of schooling in 2012 was 13.6. A small percentage (16\%) reported completing more years of education (i.e. educational gain) in 2015 than in 2012. The vast majority (82\%) of the population was employed in 2012.

\section{Proficiency gains from 2012 to 2015}

We found the mean change in literacy proficiency from 2012 to 2015 to be 1.2 scale points (related to a $0-500$ point scale) with a standard deviation of 25.4 scale points, which is not statistically different from zero $(z=1.43, p>0.05)$. Similarly, the mean

${ }^{13}$ This is sometimes termed a "null hypothesis". 
Table 1 Descriptive statistics for proficiency, practice engagement and covariate variables

\begin{tabular}{lll}
\hline Variable & Mean & $\begin{array}{l}\text { Standard } \\
\text { deviation }\end{array}$ \\
\hline Literacy 2015 & 275 & 45 \\
Literacy 2012 & 276 & 47 \\
Numeracy 2015 & 277 & 51 \\
Numeracy 2012 & 277 & 53 \\
Reading Engagement (RE) 2012 & 0.00 & 0.86 \\
Writing Engagement (WE) 2012 & 0.00 & 0.76 \\
Maths Engagement (ME) 2012 & 0.00 & 0.90 \\
Age (years) 2012 & 41.8 & 0.77 \\
Female 2012 (share) & 0.49 & 0.49 \\
Education (years) 2012 & 13.6 & 0.96 \\
Currently Employed 2012 (share) & 0.82 & 0.39 \\
Educational Gain 2012-2015 (share) & 0.16 & 0.37 \\
\hline
\end{tabular}

Notes: All numerical results are population estimates for the native German-speaking adult population, aged 16-65 in 2012. The sample size was $n=2,989$

change in numeracy proficiency over the time period was 0.6 scale points with a standard deviation of 31.3 scale points, not statistically different from zero $(z=0.61$, $p>0.05)$. Thus, overall neither literacy nor numeracy proficiency changed over the three years between 2012 and 2015. At the same time, we found considerable heterogeneity of individuals' proficiency gains, even though the population's average gain was zero. For example, as noted in our literature review above, participants' age in 2012 should be negatively related to their proficiency gains, with younger adults tending to have positive gains and older adults smaller and even negative gains (proficiency decline).

Figure 1 displays the mean proficiency gain for adults of different initial ages. As expected from previous research, we found a negative relationship between proficiency gain and age, with younger adults showing the largest average gains, and older adults showing the smallest and even negative gains. The youngest age group, the 16-24-year-olds in 2012, had mean literacy and numeracy gains of 8.7 and 11.4 scale points, respectively. This is consistent with overall findings from the longitudinal and other studies mentioned above in our literature review. Because other experiences known to influence proficiency, such as education and employment, are usually correlated with age, it is best to examine the effects of age and other demographic variables more closely in the multivariate setting of regression models, so this is what we did.

\section{Regression models of gain in literacy proficiency}

Table 2 displays eight OLS regression models for literacy proficiency gain. Each model includes literacy proficiency in 2012 and the five covariates as independent variables - age, gender, education, employment and educational gain between 


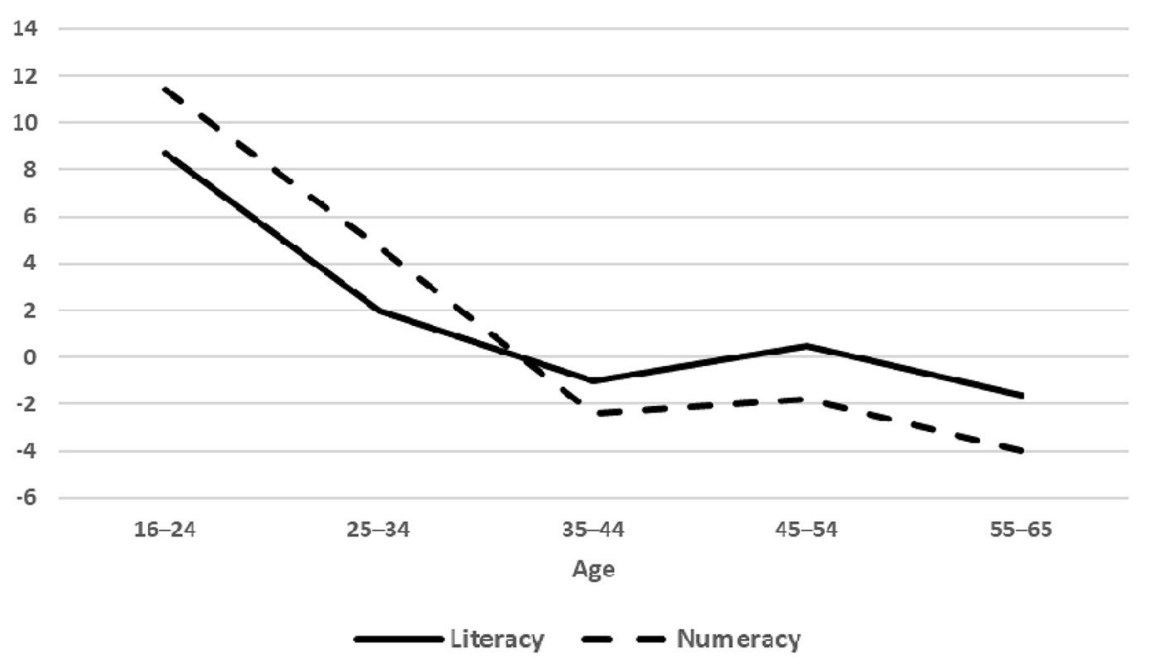

Fig. 1 Proficiency gains, 2012-2015, by age in 2012

2012 and 2015. The eight models differ with respect to the combination of practice engagement variables - RE, WE and ME - included as independent variables. Model (1) is the baseline model that includes no practice engagement variables.

In the baseline model of literacy proficiency gain, we find statistically significant negative effects of 2012 literacy proficiency and positive effects of years of education (as of 2012), as well as a statistically significant negative effect of age. The effects of gender, current employment and educational gain between 2012 and 2015 are not statistically significant. ${ }^{14}$ In general, we found this pattern of effects to be the same across the other models in the table. The negative effect of age on literacy gain from 2012 to 2015 was expected, both based on previous research and on the data shown in Figure 1.

It is noticeable that the $R^{2}$ values ${ }^{15}$ shown for the regression models are quite small, accounting for only 11 to 13 per cent of the variance in literacy proficiency gain. These small values contrast with the larger $R^{2}$ values that accompany regressions using the same covariates to predict literacy proficiency at either point in

\footnotetext{
${ }^{14}$ It is worth noting that in regression results not shown here, years of formal education was a significant positive predictor of literacy proficiency in both 2012 and 2015, as well as of literacy proficiency gain between 2012 and 2015, as shown in Table 2. However, educational gain is not a significant predictor of literacy proficiency gain, with literacy proficiency in 2012 and the other variables controlled, as shown in Table 2.

${ }^{15}$ An $R^{2}$ value expresses the proportion of the variance of one variable predicted by the values of other variables.
} 


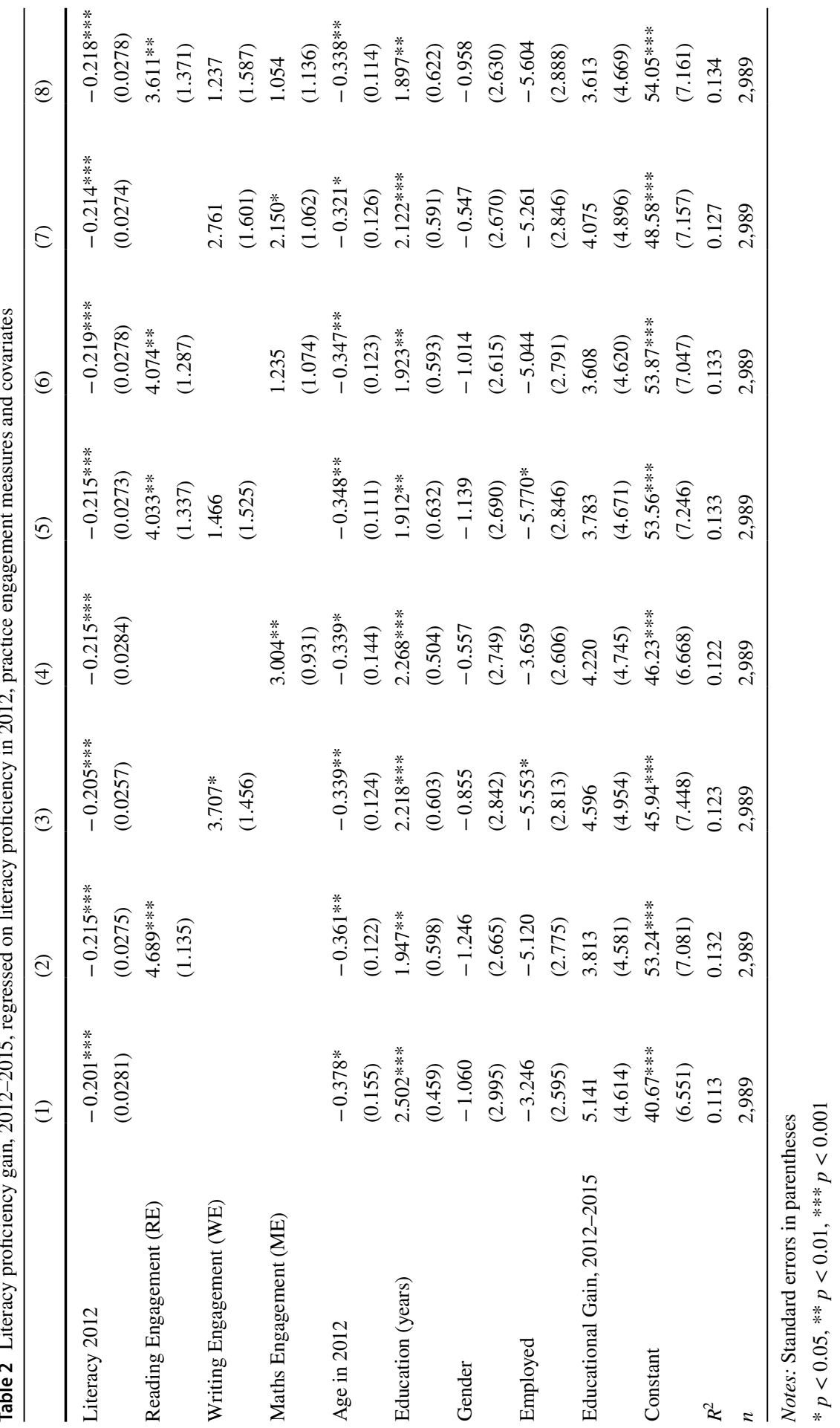


time. ${ }^{16}$ The difference between individuals' proficiency at the two points in time is more difficult to predict, partly because of the overall stability of proficiencies across the lifespan and partly because of the increased measurement error accompanying the difference between two repeated measurements.

Model (2) adds the reading engagement measure RE to the baseline model. We found RE to be a statistically significant positive predictor of literacy gain with the other variables controlled. With literacy proficiency in 2012 and other variables controlled, literacy proficiency in 2015 averages 4.69 scale points higher per unit of RE. Since RE is scaled with a standard deviation of 0.86 (Table 1), the RE increment is equivalent to about five literacy scale points per standard deviation of reading engagement.

Because of the small $R^{2}$ values involved in both models being compared, we were interested to find out whether adding RE to the baseline model would significantly improve the overall fit of Model (2) compared to the baseline model. Since Model (1) is nested in Model (2), we were able to use a likelihood ratio test to compare the two models' fit to the data. The test statistic of twice the difference in the two models' log likelihoods is asymptotically distributed as chi squared $\left(\chi^{2}\right)^{17}$ with one degree of freedom for the extra parameter RE estimated for Model (2): $\chi^{2}=63.3$, df $=1, \mathrm{p}<0.001$. We therefore rejected the null hypothesis that the two models fit the data equally well. We found that adding reading engagement to the predictive model significantly improved the overall fit.

When we look at the effects of other practice engagement variables and combinations of practice engagement variables in Models (3)-(8) in Table 2, several points stand out. First, RE remains a statistically significant and positive predictor of gain in literacy proficiency with WE and/or ME also in the model. Second, WE and ME are statistically significant predictors in some specifications (Models 3, 4 and 7), but are not as strong as RE.

These findings are consistent with the idea that the closer a set of practices is to the cognitive proficiency being assessed, the stronger the effect its practice engagement measure will have on the growth of that proficiency. Since the literacy proficiency assessed in PIAAC-L involves mastery of everyday reading tasks, we expected and found RE to be the strongest predictor of literacy proficiency growth (compared to the effects of $\mathrm{WE}$ and $\mathrm{ME}$ ). We will return to this important point after examining the corresponding numeracy proficiency results.

\section{Regression models of gain in numeracy proficiency}

Table 3 is parallel to Table 2, displaying eight OLS regression models for numeracy proficiency gain between 2012 and 2015. Overall findings are similar to those for literacy proficiency. The baseline model of numeracy proficiency gain has statistically

\footnotetext{
16 In regression models not shown here of literacy proficiency at a single point in time, covariates other than practice engagement measures accounted for 25 per cent of the variance in literacy proficiency in 2012 and 31 per cent of the variance in 2015.

17 A chi-squared value expresses how well observed data match the values predicted by a model.
} 


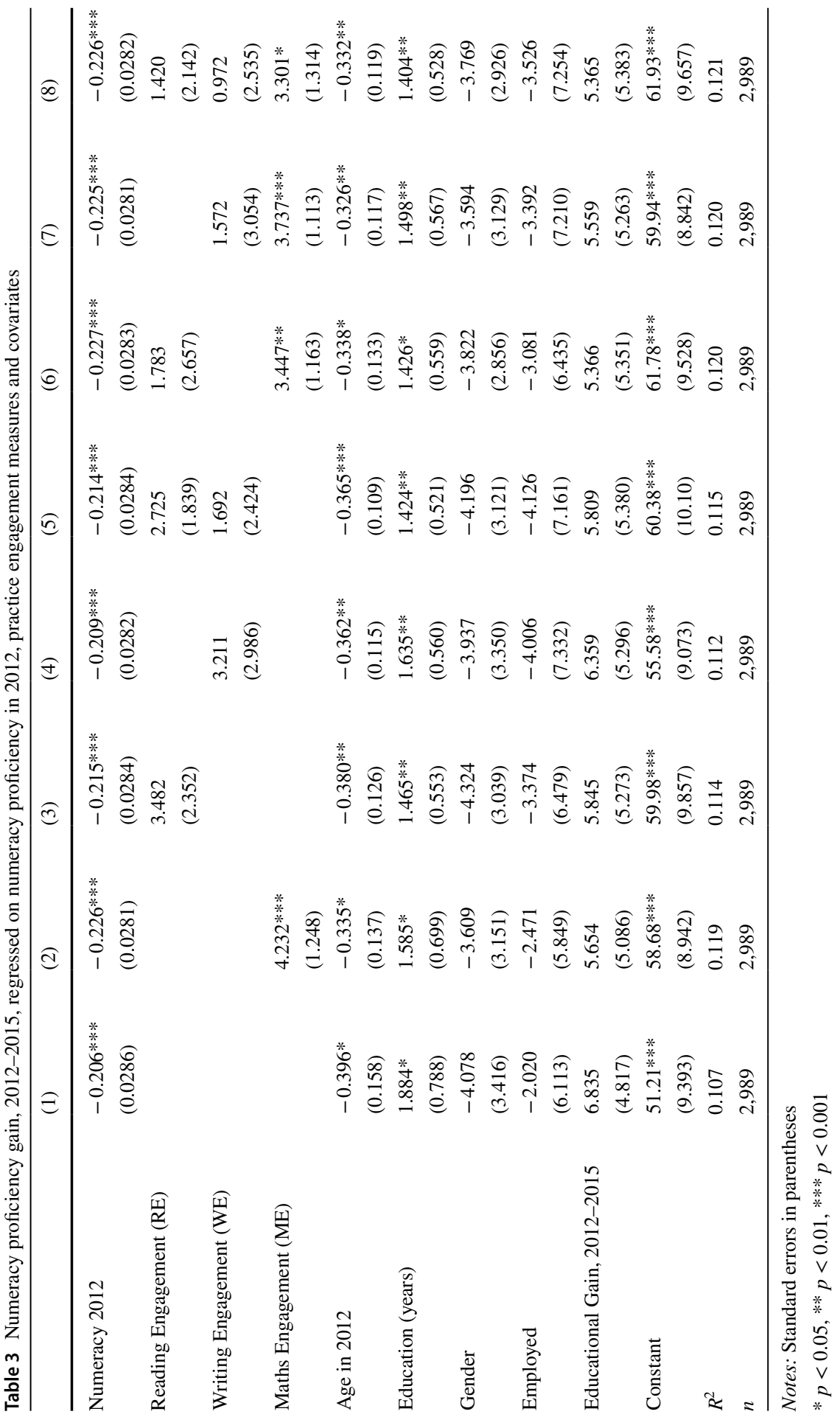


significant negative effects of 2012 numeracy proficiency and positive effects of years of education (as of 2012), as well as a statistically significant negative effect of age. The effects of gender, current employment and educational gain between 2012 and 2015 turned out not to be statistically significant. ${ }^{18}$

This pattern of covariate effects is the same that we found for literacy and holds across all the other models in Table 3. The $R^{2}$ values are in the same range as those in Table 2 for literacy proficiency, accounting for 11 to 12 per cent of the variance.

Model (2) adds the maths engagement measure ME to the baseline model. We see that ME is a statistically significant positive predictor of numeracy gain with the other variables controlled. With numeracy proficiency in 2012 and other variables controlled, numeracy proficiency gain averages 4.23 scale points more per unit of ME. Since ME is scaled with a standard deviation of 0.90 (Table 1), the ME increment is equivalent to about five numeracy scale points per standard deviation of maths engagement.

As with the literacy proficiency models, we were also interested to find out whether adding ME to the baseline model would significantly improve the overall fit of Model (2) compared to the baseline model. Since Model (1) is nested in Model (2), we were able to use a likelihood ratio test to compare how well the two models fit the data. The test statistic of twice the difference in the two models' log likelihoods is asymptotically distributed as chi-squared with one degree of freedom for the extra parameter ME estimated for Model (2): $\chi^{2}=37.8$, df $=1, \mathrm{p}<0.001$. We therefore rejected the null hypothesis that the two models fit the data equally well. We found that adding maths engagement to the predictive model significantly improved the overall fit.

Considering the effects of other practice engagement variables and combinations of practice engagement variables in Table 3, several points stand out. First, ME remains a statistically significant and positive predictor of gain in numeracy proficiency with RE and/or WE also in the model. Second, RE and WE are not statistically significant predictors of numeracy gain. These findings are consistent with the idea that the closer a set of practices is to the cognitive proficiency being assessed, the stronger the effect its practice engagement measure has on the growth of that proficiency. Since the numeracy proficiency assessed in PIAAC-L is framed around everyday maths, we expected and found ME to be the strongest predictor of numeracy proficiency growth (compared to the effects of RE and WE).

\section{Summary and discussion}

Our findings provide longitudinal support to PET using nationally representative data and proficiency measures from national and international surveys. The findings are consistent across the literacy and numeracy proficiency domains. In terms of

\footnotetext{
18 It is worth noting that in regression results not shown here, years of formal education was a significant positive predictor of numeracy proficiency in both 2012 and 2015, as well as of numeracy proficiency gain between 2012 and 2015, as shown in Table 3. But educational gain is not a significant predictor of numeracy proficiency gain, with numeracy proficiency in 2012 and the other variables controlled, as shown in Table 3.
} 
the specific questions we asked in testing PET, we found that engagement in reading practices is positively associated with the development of individuals' literacy proficiency over time. Likewise, engagement in maths practices is positively associated with the development of individuals' numeracy proficiency over time. We found considerable specificity in which set of everyday practices best predicts the growth of these proficiencies. The closer a set of practices is to the cognitive proficiency being assessed, the more strongly its practice engagement measure predicts the growth of that proficiency. For literacy, engagement in reading practices is the strongest predictor of proficiency growth. For numeracy, engagement in maths practices is the strongest predictor of proficiency growth. In each proficiency domain, we found the magnitude of the practice engagement effect to be relatively small - about five proficiency scale points over a three-year period per standard deviation of practice engagement. Other longitudinal research suggests that these practice-based proficiency gains will continue to grow as practice engagement and associated proficiency development continue over longer time intervals (Reder 2009a). Additional longitudinal research that incorporates repeated measures of both practice engagement and proficiencies at multiple points in time can help clarify and quantify these relationships.

Concerning the covariates in our model, we found age and education significantly affect the observed gains, while neither gender nor employment status proved to be a statistically significant predictor in the multivariate modelling environments. In line with previous research, we found age to be negatively related to both literacy and numeracy gains, with younger adults averaging positive gains and older adults averaging negative gains. This trend is summarised by the statistically significant negative coefficient of age in the multivariate regression models predicting proficiency gains.

Much previous research, of course, has established education as a strong positive predictor of literacy and numeracy proficiencies in adult populations at a given point in time. Our results for predicting proficiency gain between two points in time, however, appear somewhat different. ${ }^{19}$ We found years of education completed by 2012 to be a statistically significant positive predictor of proficiency gain between 2012 and 2015, indicating that education not only predicts adult proficiencies at a given point in time, it also predicts changes in adult proficiencies over time. Educational gain between 2012 and 2015, however, is not a significant predictor of proficiency gain over that period. These findings suggest that adult learners' enrolment in formal education may not serve to foster the development of either literacy or numeracy proficiency. Previous research has also indicated that job-related training does not foster proficiency gains, either (Gauly and Lechner 2019; Gauly et al. forthcoming).

It will be helpful in future research to have more refined measures of practice engagement in order to obtain sharper differentiation of how specific engagement measures are related to the growth of specific proficiencies such as literacy and

\footnotetext{
19 Our data agree with previous research; in results not included in this article, regressions for proficiencies at either point in time that include education (as of that point in time) and the other covariates - but do not include the proficiency at another point in time - show significant, positive effects of education.
} 
numeracy. The practice engagement measures we used in this study appear somewhat arbitrary in how some tasks are mapped onto specific practice engagement indexes. For example, "reading financial statements" is a constituent task of the reading engagement index $\mathrm{RE}$, but not of the maths engagement index ME, even though both literacy and numeracy proficiencies may well be involved in the performance of the task. Although research organisations have invested heavily in developing proficiency assessment frameworks and instruments, much less effort has been made to develop corresponding frameworks and instruments for measuring practice engagement (skill use). Jonas (2018, pp. 69-70) offers a number of specific methodological improvements that would be very helpful in this regard. Progress in this area may well require iterative cycles of research and development that support better theory and understanding of the relationships between specific proficiencies and practices.

Future research, examining the PIAAC-L or other longitudinal data sets, should also look more closely at the role of employment in proficiency development. Although current employment status (at the time of interviews conducted in 2012) did not have a significant effect on proficiency gain, it is quite possible that employment activities between 2012 and 2015 might have had an impact on proficiency growth. There are indications in other research that skill development may be embedded in complex interactions between characteristics of workers and their workplaces (Felstead et al. 2019; Inanc et al. 2015).

Our findings have several important implications for programme design in adult education and lifelong learning. Victoria Purcell-Gates et al. (2002) studied adult education programmes that focus on helping students successfully engage with personally meaningful reading and writing practices. They found that these programmes increase levels of everyday practice engagement. This was observed not only during students' enrolment in the programmes but also after the programmes had ended. Analyses of data from a longitudinal panel study that collected repeated measures of adults' proficiencies and levels of practice engagement found that basic skills programmes foster short-term increases in practice engagement that over time lead to longer-term changes in proficiency (Reder 2009a). Together with this research, our present findings suggest that practicecentred formal and non-formal instructional programmes may point in a promising direction for innovation in adult education and lifelong learning (Reder 2009b, Sheehan-Holt and Smith 2000).

Our study also has important implications for policymaking. Policies that foster increased adult engagement in everyday reading, writing and maths practices will support lifelong learning and proficiency growth and should broaden access to continuing education and vocational training. These outcomes are central to the fourth United Nations Sustainable Development Goal (SDG 4), which focuses on education.

There is a growing base of evidence suggesting that increased practice engagement may also have wider benefits for individuals and societies. Previous research has found that key social outcomes measured in PIAAC in numerous countries - social trust, general health, political efficacy and volunteerism - are 
all positively associated with practice engagement, even with proficiency, education and other variables controlled (Jonas 2018; Reder 2017). These relationships hold for general adult populations, for low-proficiency adult populations and for other vulnerable populations such as incarcerated adults (Reder 2019b). Further research is needed that tracks these and other outcomes longitudinally along with levels of practice engagement in order to improve our understanding of the causalities that may be involved, and the potential impact of practice engagementcentred policies and programmes.

Acknowledgements This research was supported by a grant from the German Research Foundation (DFG) to Clemens M. Lechner (Grant Number LE 4001/1-1). This project is part of the DFG Priority Programme 1646 - Education as a Lifelong Process.

Open Access This article is licensed under a Creative Commons Attribution 4.0 International License, which permits use, sharing, adaptation, distribution and reproduction in any medium or format, as long as you give appropriate credit to the original author(s) and the source, provide a link to the Creative Commons licence, and indicate if changes were made. The images or other third party material in this article are included in the article's Creative Commons licence, unless indicated otherwise in a credit line to the material. If material is not included in the article's Creative Commons licence and your intended use is not permitted by statutory regulation or exceeds the permitted use, you will need to obtain permission directly from the copyright holder. To view a copy of this licence, visit http://creativecommons.org/licen ses/by/4.0\%.

\section{References}

Avvisati, F., \& Keslair, F. (2017 [2014]). REPEST: Stata module to run estimations with weighted replicate samples and plausible values [revised 23 Mar 2017]. Statistical Software Components S457918. Chestnut Hill, MA: Boston College Department of Economics.

Barrett, G., \& Riddell, W. (2016). Ageing and literacy skills: Evidence from IALS, ALL and PIAAC. OECD Education Working Papers, No. 145. EDU/WKP(2016)19. Paris: OECD Publishing. Retrieved 2 January 2020 from https://doi.org/10.1787/5jlphd2twps1-en.

Billett, S. (2004). Workplace participatory practices: Conceptualising workplaces as learning environments. Journal of Workplace Learning, 16(6), 312-324.

Brooks, G., Davies, R., Ducke, L., Hutchison, D., Kendall, S., \& Wilkin, A. (2001). Progress in adult literacy: Do learners learn?. London: The Basic Skills Agency.

Bynner, J., \& Parsons, S. (1998). Use it or lose it? The impact of time out of work on literacy and numeracy skills. London: Basic Skills Agency. Retrieved 2 January 2019 from https://files.eric.ed.gov/fullt ext/ED430160.pdf.

de Grip, A. \& van Loo, J. (2002). The economics of skills obsolescence: A review. In A. de Grip, J. van Loo \& K. Mayhew (Eds) The economics of skills obsolescence (pp. 1-26). Research in Labor Economics, vol. 21. Bingley: Emerald Group Publishing.

Desjardins, R., \& Warnke, A.J. (2012). Ageing and skills: A review and analysis of skill gain and skill loss over the lifespan and over time. OECD Education Working Papers, No. 72. EDU/WKP(2012)9. Paris: OECD Publishing. Retrieved 2 January 2020 from https://doi.org/10.1787/19939019.

Dinis da Costa, P., Rodrigues, M., Vera-Toscano, E., \& Weber, A. (2014). Education, adult skills and social outcomes: Empirical evidence from the Survey on Adult Skills (PIAAC 2013). Report EUR 26626 EN. Luxembourg: Publications Office of the European Union. Retrieved 2 January 2020 from https://publications.jrc.ec.europa.eu/repository/bitstream/JRC89591/skills_social_outcomes_piaac _final_version_pubsy.pdf.

Edin, P.-A., \& Gustavsson, M. (2008). Time out of work and skill depreciation. Industrial and Labor Relations Review, 61(2), 163-180. 
Felstead, A., Gallie, D., Green, F., \& Henseke, G. (2019). The determinants of skills use and work pressure: A longitudinal analysis. Economic and Industrial Democracy, 40(3), 730-754.

Gauly, B., \& Lechner, C. (2019). Self-perfection or self-selection? Unraveling the relationship between job-related training and adults' literacy skills. PLOS ONE, 14(5), Art. e0215971. Retrieved 2 January 2020 from https://doi.org/10.1371/journal.pone.0215971.

Gauly, B., Reder, S., \& Lechner, C. (forthcoming). Does job-related training benefit adult numeracy skills? Evidence from a German panel study. Zeitschrift für Erziehungswissenschaft.

GESIS (Leibniz Institute for the Social Sciences) (n.d.). PIAAC related projects: PIAAC-Longitudinal (PIAAC-L). [dedicated webpage]. Cologne: GESIS. Retrieved 6 March 2020 from https://www. gesis.org/en/piaac/projects.

Green, F. (2013). Skills and skilled work: An economic and social analysis. Oxford, UK: Oxford University Press.

Green, D.A., \& Riddell, W.C. (2013). Ageing and literacy skills: Evidence from Canada, Norway and the United States. Labour Economics, 22(C), 16-29.

Hamel, J.-F., Challet-Bouju, G., Sebille, V., \& Hardouin, J. B. (2016). Partial credit model: Estimations and tests of fit with pcmodel. Stata Journal, 16(2), 464-481.

Hampf, F., Wiederhold, S., \& Woessman, L. (2017). Skills, earnings, and employment: Exploring causality in the estimation of returns to skills. Large-scale Assessments in Education, 5, Art. 12. Retrieved 2 January 2020 from https://doi.org/10.1186/s40536-017-0045-7.

Hanushek, E., \& Woessman, L. (2015). Universal basic skills: What countries stand to gain. Paris: OECD Publishing Retrieved 2 January 2020 from https://doi.org/10.1787/9789264234833-en.

Hanushek, E. A., Schwerdt, G., Wiederhold, S., \& Woessmann, L. (2015). Returns to skills around the world: Evidence from PIAAC. European Economic Review, 73(C), 103-130.

Inanc, H., Zhou, Y., Gallie, D., Felstead, A., \& Green, F. (2015). Direct participation and employee learning at work. Work and Occupations, 42(4), 447-475.

Jonas, N. (2018). Numeracy practices and numeracy skills among adults. OECD Education Working Papers, No. 177. EDU/WKP(2018)13. Paris: OECD Publishing. Retrieved 2 January 2020 from https://doi.org/10.1787/8f19fc9f-en.

Masters, G. N. (1982). A Rasch model for partial credit scoring. Psychometrika, 47(2), 149-174.

OECD (Organisation for Economic Co-operation and Development) (2013). OECD Skills Outlook 2013: First results from the Survey of Adult Skills. Paris: OECD Publishing. Retrieved 2 January 2020 from https://doi.org/10.1787/9789264204256-en.

OECD (2016). Skills matter: Further results from the Survey of Adult Skills. OECD Skills Studies series. Paris: OECD Publishing. Retrieved 2 January 2020 from https://doi.org/10.1787/9789264258 051-en.

Paccagnella, M. (2016). Age, ageing and skills: Results from the Survey of Adult Skills. OECD Education Working Papers, No. 132. Paris: OECD Publishing. EDU/WKP(2016)6. Retrieved 2 January 2020 from https://doi.org/10.1787/5jm0q1n381vc-en.

PIAAC Literacy Expert Group (2009). PIAAC literacy: A conceptual framework. OECD Education Working Papers, No. 34. Paris: OECD Publishing. EDU/WKP(2009)13. Retrieved 2 January 2020 from https://doi.org/10.1787/220348414075.

PIAAC Numeracy Expert Group (2009). PIAAC numeracy: A conceptual framework. OECD Education Working Papers, No. 35. EDU/WKP(2009)14. Paris: OECD Publishing. Retrieved 2 January 2020 from https://doi.org/10.1787/220337421165.

Purcell-Gates, V., Degener, S. C., Jacobson, E., \& Soler, M. (2002). Impact of authentic adult literacy instruction on adult literacy practices. Reading Research Quarterly, 37(1), 70-92.

Reder, S. (1994). Practice engagement theory: A sociocultural approach to literacy across languages and cultures. In B. Ferdman, R.-M. Weber, \& A. Ramirez (Eds.), literacy across languages and cultures (pp. 33-74). Albany, NY: SUNY Albany Press.

Reder, S. (2009a). Scaling up and moving in: Connecting social practices views to policies and programs in adult education. Literacy and Numeracy Studies, 16(2), 35-50.

Reder, S. (2009b). The development of literacy and numeracy in adult life. In S. Reder \& J. Bynner (Eds.), Tracking adult literacy and numeracy skills: Findings from longitudinal research (pp. 59-84). New York/London: Routledge.

Reder, S. (2017). Adults' engagement in reading, writing and numeracy practices. Portland, OR: Portland State University. Retrieved 16 March 2020 from http://archives.pdx.edu/ds/psu/21693. 
Reder, S. (2019a). Developmental trajectories of adult education students: Implications for policy, research, and practice. In D. Perin (Ed.), Wiley handbook of adult literacy (pp. 429-450). Hoboken, NJ: Wiley Blackwell.

Reder, S. (2019b). Numeracy imprisoned: Skills and practices of incarcerated adults in the United States. ZDM Mathematics Education (online first). https://doi.org/10.1007/s11858-019-01094-0.

Schwerdt, G., \& Wiederhold, S. (2018). Literacy and growth: New evidence from PIAAC [online article]. Retrieved 16 March 2020 from http://www.dataangel.ca/docs/LiteracyandGrowth_revised_Octob er2018.pdf.

Sheehan-Holt, J., \& Smith, M. C. (2000). Does basic skills education affect adults' literacy proficiencies and reading practices? Reading Research Quarterly, 35(2), 226-243.

Skule, S. (2014). Learning conditions at work: A framework to understand and assess informal learning in the workplace. International Journal of Training and Development, 8(1), 8-20.

Smith, M. C. (1996). Differences in adults' reading practices and literacy proficiencies. Reading Research Quarterly, 31(2), 196-219.

Smith, M. C. (2009). Literacy in adulthood. In M. C. Smith (Ed.), Handbook of research on adult learning and development (pp. 601-635). New York/London: Routledge.

UIS (UNESCO Institute for Statistics) (2018). Quick guide to education indicators for SDG 4. Montreal: UIS. Retrieved 2 January 2020 from http://uis.unesco.org/sites/default/files/documents/quick-guide -education-indicators-sdg4-2018-en.pdf.

Vézina, S., \& Bélanger, A. (2019). Impacts of education and immigration on the size and skills of the future workforce. Demographic Research, 41(12), 331-366.

Wilks, S. S. (1938). The large-sample distribution of the likelihood ratio for testing composite hypotheses. The Annals of Mathematical Statistics, 9(1), 60-62.

Wolf, A., \& Jenkins, A. (2014). Do "learners" always learn? The impact of workplace adult literacy courses on participants’ literacy skills. British Educational Research Journal, 40(4), 585-609.

Publisher's Note Springer Nature remains neutral with regard to jurisdictional claims in published maps and institutional affiliations.

Stephen Reder is Professor Emeritus at Portland State University in the United States. His career has involved research, teaching and service activities in education, workplace and community settings. His research focuses on adults' lifelong and life-wide literacy, numeracy, digital literacy and second-language development processes. He has a $\mathrm{PhD}$ from the Rockefeller University in psychology. He is currently researching the long-term impact of adult education on economic, social and lifelong learning outcomes. He serves on the advisory boards of numerous organisations and journals and works with adult education researchers, practitioners and policymakers at local, state, national and international levels.

Britta Gauly is a researcher at the Department of Survey Design and Methodology at GESIS - LeibnizInstitute for the Social Sciences in Mannheim, Germany. She is currently working in the German national team for the Programme of the International Assessment of Adult Competencies (PIAAC). Before joining GESIS in 2015, she studied Economics at the Universities of Berlin, Bonn, Freiburg, and Lund. Her main research interests comprise topics on adult education and training and skills development in adult life.

Clemens Lechner is the head of the "Scale Development and Documentation" team at the Department of Survey Design and Methodology at GESIS - Leibniz-Institute for the Social Sciences in Mannheim, Germany. He obtained his doctoral degree in developmental psychology from the University of Jena, Germany. Subsequently, he was a postdoctoral fellow in the International Pathways to Adulthood Programme of the Jacobs foundation, specialising in youths' educational and labour market transitions. Since joining GESIS in 2016, he has been involved as a principal and co-principal investigator in several major research projects on adults' cognitive and socio-emotional skills development over the life span. 


\section{Affiliations}

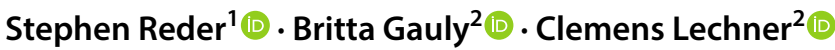

Britta Gauly

britta.gauly@gesis.org

Clemens Lechner

clemens.lechner@gesis.org

1 Portland State University, Portland, OR, USA

2 GESIS Leibniz Institute for the Social Sciences, Mannheim, Germany 